\title{
Fibromuscular Dysplasia of the Coronary Arteries: A Case Report and Review of the Literature
}

\author{
Julia KUZYK', Oksana BOIKO², Taras STETSKO³ \\ 'Danylo Halytsky Lviv National Medical University, Medical Department, LVIV, UKRAINE \\ ${ }^{2}$ Lviv Regional Pathology Bureau, LVIV, UKRAINE \\ ${ }^{3}$ Districtical Hospital, GDANSK, POLAND
}

\begin{abstract}
Fibromuscular dysplasia is a nonatherosclerotic and non-inflammatory vascular disease with primary lesion of renal and internal carotid arteries. We present a neonatal case of fibromuscular dysplasia who died on the second day of life. The newborn suffered from fibromuscular dysplasia of the coronary arteries and a congenital heart defect. The interesting feature of this case was the formation of aneurysms of the coronary arteries with pulmonary atresia.
\end{abstract}

This case demonstrates a casuistically rare form of association between fibromuscular dysplasia of the coronary arteries and pulmonary artery atresia.

Key Words: Aneurysm, Coronary arteries, Fibromuscular dysplasia, Pulmonary atresia

\section{INTRODUCTION}

Fibromuscular dysplasia (FMD) is a nonatherosclerotic and non-inflammatory vascular disease with primary lesion of renal and internal carotid arteries. FMD was first described by Leadbetter and Burkland in 1938. They observed a 5-year old boy with hypertension and atrophy of the right kidney. Pathological changes manifested as renal artery stenosis caused by "deposits of subintimal masses in smooth muscle cells" with thinning of the arterial wall and distal damage (1). The term "fibromuscular hyperplasia" was introduced in 1958 by McCormack et al. The authors collected four cases of "fibromuscular hyperplasia" over 20 years and first described in detail the essence of the pathological changes (2). Whereas clinical FMD is often asymptomatic, it is described only in a few cases. Only with the introduction of angiography has the disease started to be diagnosed more frequently.

FMD is a rare disease with a variety of pathological changes in the affected arteries and all cases require detailed investigation. Analysis of individual cases is very important for explanation of the general pathological concepts. The aim of our research was to analyze a rare case of fibromuscular dysplasia of the coronary arteries and compare it with the literature.

(Turk Patoloji Derg 2018, 34:269-273)

Received : 28.08.2015 Accepted : 12.10.2015

\section{MATERIAL and METHODS}

An autopsy was performed in a newborn with a congenital heart defect-pulmonary artery atresia combined with fibromuscular dysplasia of the coronary arteries. Histopathological changes of the coronary arteries were studied by standard and elective histological techniques (Hematoxylin \& Eosin, Hart's elastin, Heidenhain's azan).

A child was born via spontaneous vaginal delivery with a birth weight of $3400 \mathrm{~g}$ and body length of $51 \mathrm{~cm}$. The Apgar score was 8 . After birth, the child's condition became worse. We detected muscular hypotonia, hyporeflexia, cyanosis, and a rough systolic murmur at the second left intercostal space. With each passing hour, the signs of heart failure increased. On the second day of life, the child died.

Clinical diagnosis of the cyanotic congenital heart defect was tetralogy of Fallot and transposition of main vessels.

Necropsy examination revealed central cyanosis. The heart weighed $40 \mathrm{~g}$ (normal weight - $21 \mathrm{~g}$ ); there was a spherical heart shape due to left ventricular dilatation. The volume of the right heart chambers were less than half of the left. Over the course of the coronary arteries, there were multiple rounded protrusions that resembled a "string of beads"; their diameter ranged from 0.3 to $1.0 \mathrm{~cm}$. The largest

Correspondence: Oksana BOIKO

Lviv Regional Pathology Bureau, LVIV, UKRAINE

E-mail: bo_ok.lviv@mail.ru Phone: +38 0687640777 
protrusion originated from the proximal left anterior descending coronary artery, the smallest from the posterior descending artery. The protrusions were formed by a significantly thick and dense wall with marked narrowing of the coronary artery lumen. The largest protrusion, 1.0 $\mathrm{cm}$, represented an aneurysm with a lumen diameter of 0.5 $\mathrm{cm}$ and wall thickness of $0.25 \mathrm{~cm}$. In serial cross-sections of the myocardium, we intramural vessels with a dense white wall. The oval window was covered by a thin, tense membrane that formed the valve that opened into the left atrium. In the right ventricle, the access to the pulmonary artery was absent. The mouth of the pulmonary artery was replaced by dense light gray tissue. A narrow blind end of the trunk of the pulmonary artery was located $0.5 \mathrm{~cm}$ above the atrioventricular ring. The pulmonary artery expanded gradually and branched typically. Other arteries were formed correctly.

Histopathological study of the coronary arteries revealed pronounced vascular wall fibrosis that formed a cushion and dramatically narrowed the star-shaped lumen. We determined smooth muscle cell hyperplasia in the subintimal layer and pronounced proliferation of collagen fibers in the intima and media. The connective tissue in the adventitia and periadventitia formed muff-like structures (Figure 1A,B). The distribution of the layers missing in the vascular wall presented an array of disparate elastic fibers with multiple fragmentations, lysis and hypochromia. The periadventitia was separated by hyperchromic elastic fibers and presented beams of the arranged collagen fibers (Figure $2 \mathrm{~A}, \mathrm{~B}$ ). The aneurysm was constructed of dense irregular connective tissue structures - multidirectional collagen fibers and numerous thin hypochromic and split elastic fibers (Figure 3). In other sections the aneurysm, the wall was twisted and irregularly thickened (Figure 4). Intramural arteries of the heart presented a muff-like form of periadventitia fibrosis, and hyperplasia of muscle fibers in the media (Figure 5). The myocardium presented fragmentation in the cardiomyocytes, contractures and interstitial edema.

Pathology diagnosis of the congenital heart defect was pulmonary artery atresia and fibromuscular dysplasia of the coronary arteries with multiple aneurysms.

\section{DISCUSSION}

The described case shows the unique data about FMD. FMD primarily affects the renal artery (60-70\%) and carotid arteries (25-30\%) (3-8). FMD involving the coronary arteries has been verified in separate cases. Lüscher et al. described coronary artery involvement only in two cases among 92 patients with FMD (9). Pate et al. for the first time diagnosed coronary artery involvement in vivo by angiographic examination (10). They described FMD as lesion of the middle or distal segment of the anterior circumflex branches of the left anterior descending coronary artery in seven premenopausal women. At that time, FMD of the coronary arteries had been determined as the cause of sudden cardiac death only with autopsy case reports (11-16). James TN found nine cases of FMD involving the coronary arteries of small caliber in a retrospective study of 1000 cases of cardiac death in 30 years (17). The lesion was focal - only a few millimeters - and therefore was not detected angiographically. Clinically, all nine women
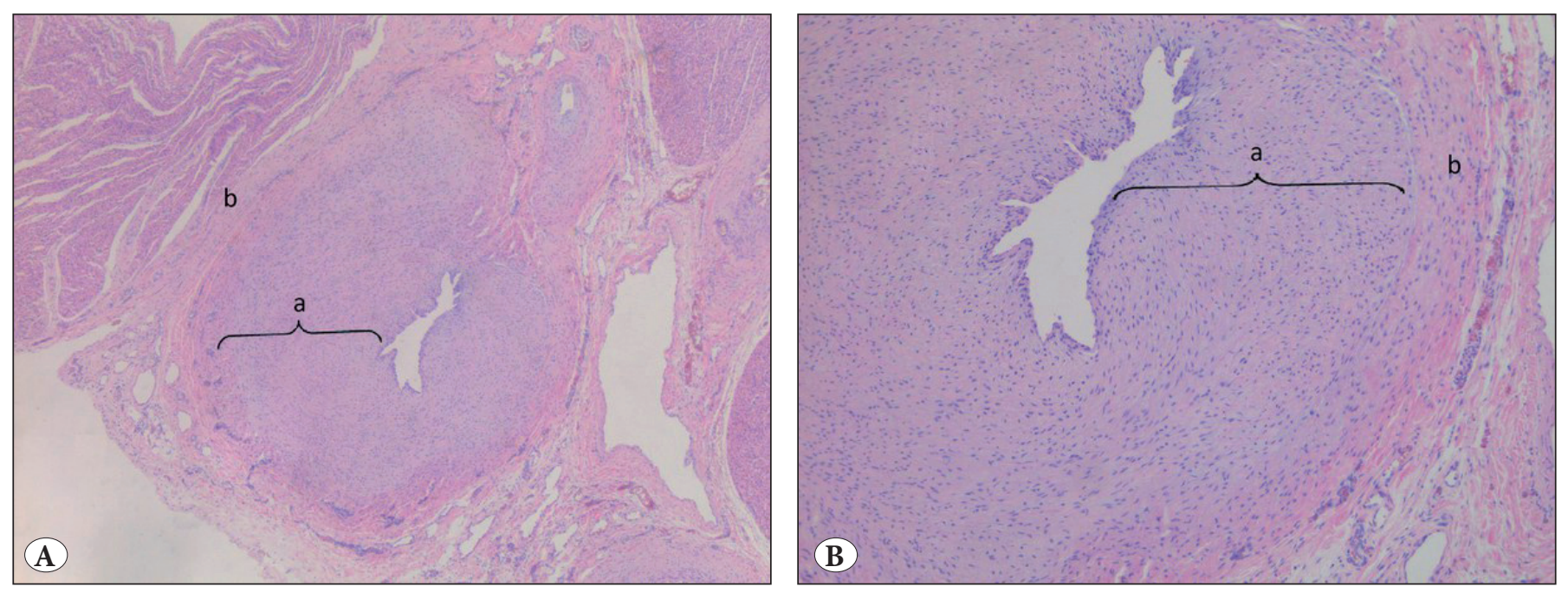

Figure 1: A) The left coronary artery with a cushion-like form of protrusion, star-shaped vascular lumen (a) pronounced proliferation of collagen fibers in the intima and media; (b) muff-like proliferation of connective tissue in the adventitia and periadventitia (H\&E; $\mathrm{x} 40$ ). B) High magnification of Figure $1 \mathrm{~A}(\mathrm{H} \& \mathrm{E} ; \mathrm{x} 100)$. 

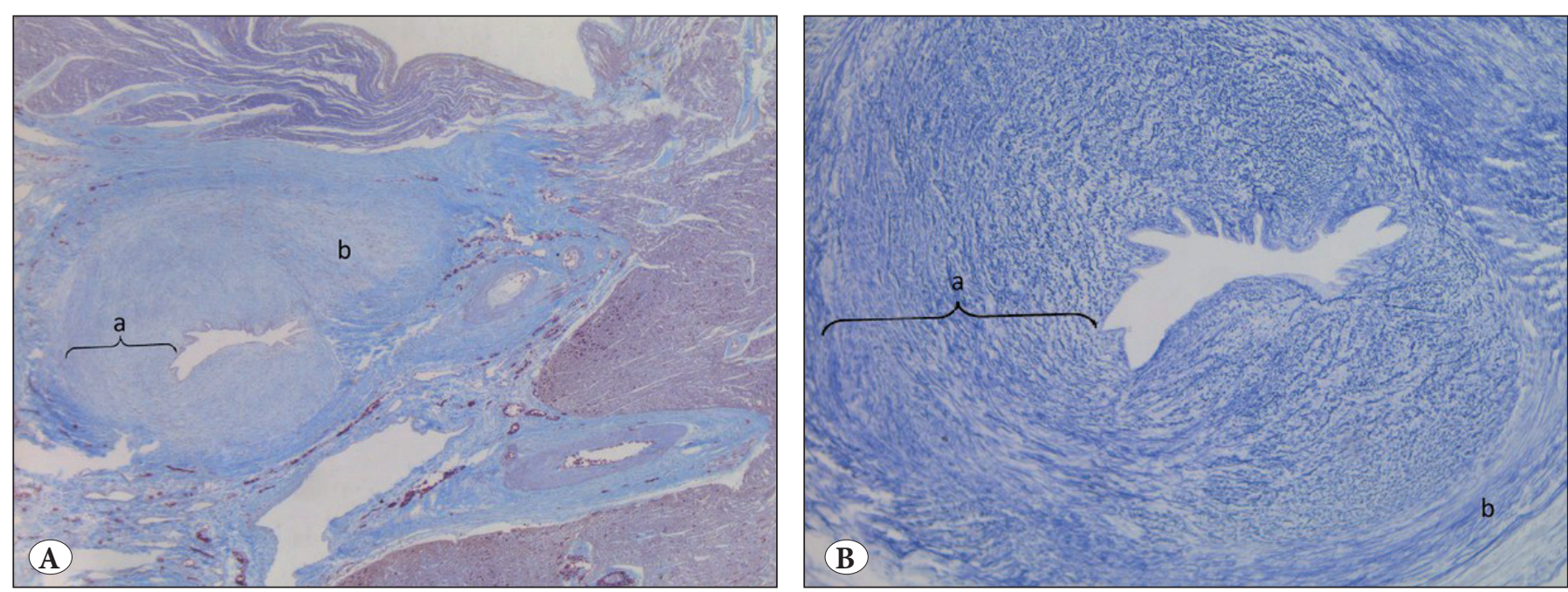

Figure 2: A) The left coronary artery: (a) the division into layers is absent, array of disparate elastic fibers with severe degenerative changes; (b) beams of the arranged collagen fibers and hyperchromic elastic fibers in the periadventitia (Heidenhain's azan; x40). B) High magnification of Figure 2 A (Heidenhain's azan; x100).

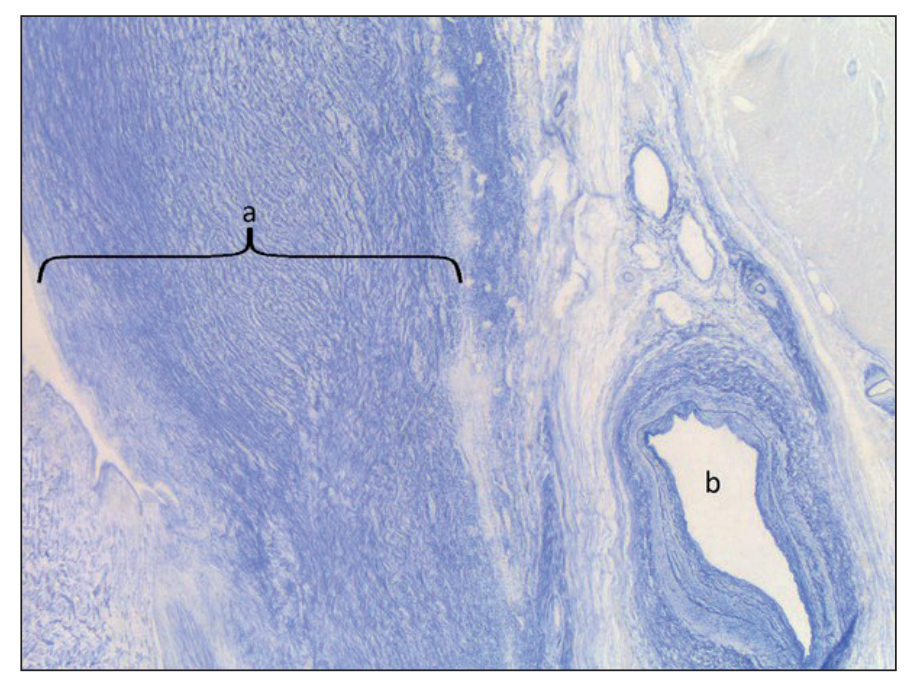

Figure 3: Aneurysm of the left coronary artery: twisted shape and irregularly thickened wall (a); subepicardial coronary artery (b) with degenerative changes of elastic fibers (Heidenhain's azan; x40).

died due to essential hypertension. In 2006, Huizar et al. first identified FMD of the coronary arteries as a cause of myocardial infarction in three middle-aged women (18). The heart attack was caused by coronary artery dissection with the development of intramural hematoma.

Development of FMD in infants has been described extremely rarely. It is known that FMD is a disease of women aged 40-60 years. In this case, we can think of innate disease, proven by the combination of FMD and congenital heart defect in a newborn baby. Some cases of FMD in twins and family members have been published $(8,19)$. Some studies

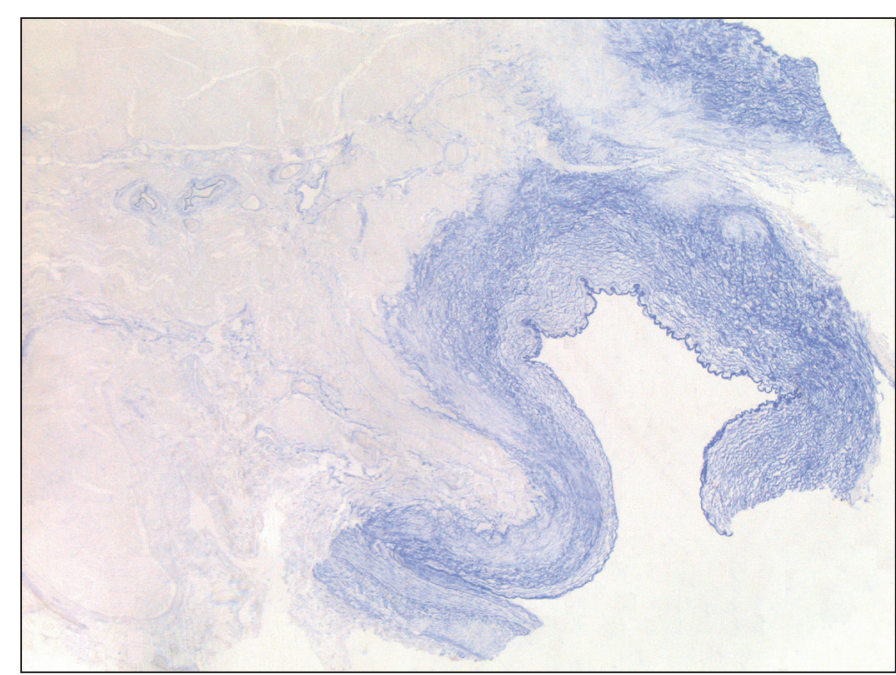

Figure 4: Aneurysm of the left coronary artery: greatly thickened wall constructed by dense irregular connective tissue structures (Heidenhain's azan; x40).

noted the combinations of FMD and pheochromocytoma (20), ergotism, a1-antitrypsin deficiency syndrome, EhlersDanlos syndrome type IV (21), Alport syndrome (4), cystic medionecrosis, Marfan syndrome, and coarctation of the aorta (22). There was no family history or other factors of the disease in the described case.

FMD of the coronary arteries typically manifests as dissection with the development of ischemic complications. Aneurysms as a complication of FMD are often described mainly in the kidney, gastric and splenic artery $(1,3,4-6)$. In this case, the coronary arteries revealed no evidence of dissection. 


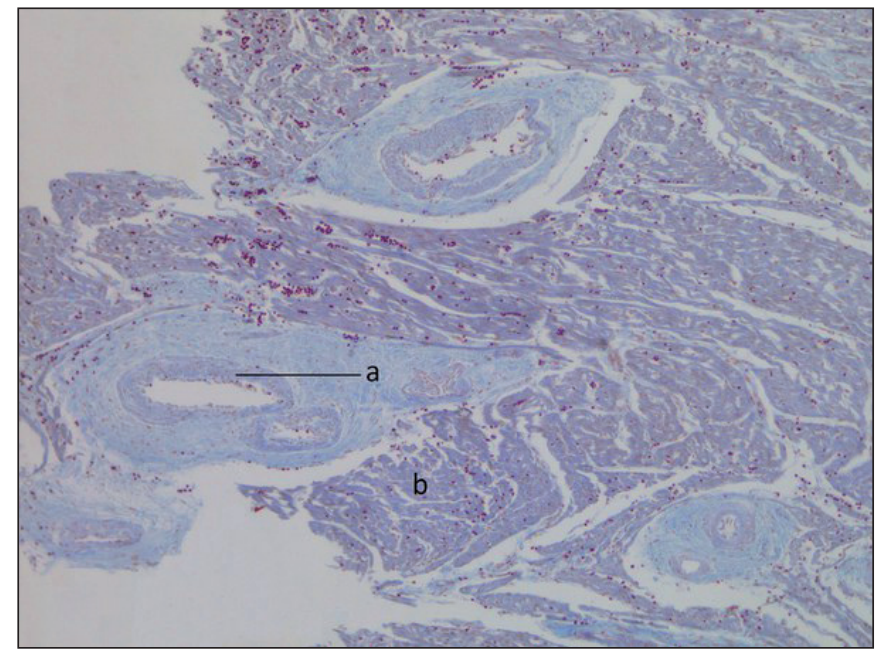

Figure 5: Myocardium of the left ventricular: (a) intramural arteries presents with muff-like form of periadventitia fibrosis, hyperplasia of muscle fibers in the media; (b) fragmentation in cardiomyocytes, contractures and interstitial edema (Heidenhain's azan; $\mathrm{x} 40$ ).

In this case, the pathological changes implicate all layers of the coronary arteries walls and spread to periadventitia. The pathological classification scheme for fibromuscular lesions proposed by Harrison and McCormack in 1971 $(2,23)$ and supplemented by Stanley et al. (1975) (24) is based on the arterial layer - intima, media, or adventitia - in which the lesion predominates. Intimal fibroplasia occurs in less than 10 percent of patients with arterial fibrodysplasia $(23,24)$. Angiographically, it may appear as a focal, concentric stenosis; a long, smooth narrowing similar to that seen in large-artery vasculitides such as giantcell arteritis or Takayasu's arteritis (3); or a redundancy of the artery. Medial fibroplasia, which is characterized by its classic "string of beads" appearance, represents the most common dysplastic lesion $(23,24)$. Typically, the beading is larger than the normal caliber of the artery and is located in the middle-to-distal portion of the artery. Histologically, there is involvement of the media, whereas the intima, internal elastic lamina, and adventitia are preserved. The lesion of perimedial fibroplasia is characterized by a homogeneous collar of elastic tissue at the junction of the media and the adventitia. The elastic elements of the media and intima appear normal. Perimedial fibroplasia is diagnosed when focal stenoses and, occasionally, multiple constrictions are observed, often with a robust collateral network. The "beads" are usually less numerous than in medial fibroplasia and are typically smaller in diameter than the normal caliber of the artery Medial hyperplasia accounts for less than 1 percent of arterial stenoses and may be indistinguishable angiographically from intimal fibroplasia (25). Adventitial (periarterial) hyperplasia is the rarest type of fibrodysplastic lesion $(23,24)$. Although there is currently limited angiographic information, sharply localized, tubular areas of stenosis have been observed.

We have described changes in the coronary arteries that did not fit any of the above-mentioned types of FMD. It can be interpreted as combination of four types of fibroplasia: intimal, medial, adventitial and periarterial. This phenomenon has not yet been described in any review of FMD.

Another feature of the case is affection of the coronary arteries of a different caliber from the main trunk to intramural branches. FMD of the coronary arteries was not a major factor of thanatogenesis. Child death was caused by a severe congenital heart defect incompatible with life.

In conclusion, the feature of this case is casuistically rare form of a combination between fibromuscular dysplasia involving the coronary arteries and congenital heart defect - pulmonary artery atresia. This case demonstrates innate FMD and presents a total coronary artery lesion with the formation of aneurysms.

\section{REFERENCES}

1. Leadbetter WF, Burkland CE. Hypertension in unilateral renal disease. J Urol. 1938;39:611-26.

2. McCormack LJ, Hazard JB, Poutasse EF. Obstructive lesions of the renal artery associated with remediable hypertension. Am J Pathol. 1958;34:582.

3. Begelman SM, Olin JW. Fibromuscular dysplasia. Curr Opin Rheumatol. 2000;12:41-7.

4. Slovut DP, Olin JF. Fibromuscular dysplasia. N Engl J Med. 2004;350:1862-71.

5. Kuzyk YuI. Fibromuscular dysplasia of vessels. Heart and Vessels. 2006;4:101-6.

6. Curry TK, Messina LM. Fibromuscular dysplasia: When is intervention warranted. Semin Vasc Surg. 2003 Sep;16:190-9.

7. Persu A, Touze E, Mousseaux E, Barral X, Joffre F, Plouin PF. Diagnosis and management of fibromuscular dysplasia: An expert consensus. Eur J Clin Invest. 2012;42:338-47.

8. Suzuki H, Daida H, Sakurai H, Yamaguchi H. Familial fibromuscular dysplasia of bilateral brachial arteries. Heart. 1999;82:251-2.

9. Lüscher TF, Keller HM, Imhof HG, Greminger P, Kuhlmann U, Largiadèr F, Schneider E, Schneider J, Vetter W. Fibromuscular hyperplasia: Extension of the disease and therapeutic outcome. Results of the University Hospital Zurich Cooperative Study on Fibromuscular Hyperplasia. Nephron. 1986;44:109-14.

10. Pate GE, Lowe R, Buller CE. Fibromuscular dysplasia of the coronary and renal arteries? Catheter Cardiovasc Interv. 2005;64:138-45. 
11. Biando C, Klimusina J, Suerder D, Gallino A. Coronary fibromuscular dysplasia: A rare cause of familial acute coronary syndrome. Case report and review of the literature. Cardiovascular Medicine. 2014;17:283-8.

12. Lie JT, Berg KK. Isolated fibromuscular dysplasia of the coronary arteries with spontaneous dissection and myocardial infarction. Hum Pathol. 1987;18:654-56.

13. Mortensen KH, Thuesen L, Kristensen IB, Christiansen EH. Spontaneous coronary artery dissection: A Western Denmark Heart Registry study. Catheter Cardiovasc Interv. 2009;74:71017.

14. Ropponen KM, Alafuzoff I. A case of sudden death caused by fibromuscular dysplasia. J Clin Pathol. 1999;52:541-42.

15. Pretty HC. Dissecting aneurysm of coronary artery in a woman aged 42: Rupture. Br Med J. 1931;1:667.

16. Zack F, Terpe H, Hammer U, Wegener R. Fibromuscular dysplasia of coronary arteries as a rare cause of death. Int J Legal Med. 1996;108:215-8.

17. James TN. Morphologic characteristics and functional significance of focal fibromuscular dysplasia of small coronary arteries. Am J Cardiol. 1990;65:12-22.

18. Huizar JF, Awasthi A, Kozman H. Fibromuscular dysplasia and acute myocardial infarction: Evidence for a unique clinical and angiographic pattern. J Invasive Cardiol. 2006;18:E99-101.
19. Pannier-Moreau I, Grimbert P, Fiquet-Kempf B, Vuagnat A, Jeunemaitre X, Corvol P, Plouin PF. Possible familial origin of multifocal renal artery fibromuscular dysplasia. J Hypertens. 1997;15:1797-801.

20. De Mendonca WC, Espat PA. Pheochromocytoma associated with arterial fibromuscular dysplasia. Am J Clin Pathol. 1981;75:749-54.

21. Schievink WI, Limburg M. Angiographic abnormalities mimicking fibromuscular dysplasia in a patient with EhlersDanlos syndrome, type IV. Neurosurgery. 1989;25:482-3.

22. Schievink WI, Bjornsson J, Piepgras DG. Coexistence of fibromuscular dysplasia and cystic medial necrosis in a patient with Marfan's syndrome and bilateral carotid artery dissections. Stroke. 1994;25:2492-6.

23. Harrison EG Jr, McCormack LJ. Pathologic classification of renal arterial disease in renovascular hypertension. Mayo Clin Proc. 1971;46:161-7.

24. Stanley JC, Gewertz BL, Bove EL, Sottiurai V, Fry WJ. Arterial fibrodysplasia: Histopathologic character and current etiologic concepts. Arch Surg. 1975;110:561-6.

25. Kincaid OW, Davis GD, Hallermann FJ, Hunt JC. Fibromuscular dysplasia of the renal arteries: Arteriographic features, classification, and observation on natural history of the disease. Am J Roentgenol Radium Ther Nucl Med. 1968;104:271-82. 